\title{
Smart Energy Management Policy in India-A Review
}

\author{
Komali Yenneti ${ }^{1}$, Riya Rahiman ${ }^{2}$, Adishree Panda ${ }^{2} \mathbb{D}$ and Gloria Pignatta ${ }^{1, * \mathbb{D}}$ \\ 1 Faculty of Built Environment, University of New South Wales (UNSW), Sydney 2052, Australia \\ 2 Centre for Urban Planning \& Governance, TERI, New Delhi 110003, India \\ * Correspondence: g.pignatta@unsw.edu.au
}

Received: 29 June 2019; Accepted: 17 August 2019; Published: 21 August 2019

\begin{abstract}
India accounts for six per cent of the world's primary energy consumption. Rapid urbanization and rapid urban population growth have had a serious impact on energy consumption and subsequent carbon emissions. In particular, cities face a complex and interrelated set of challenges across different sectors (building environment, mobility, water and waste management and public services). Re-examining these challenges by integrating smart energy management (SEM) principles is critical for sustainable and low-carbon urban development. In addition, managing energy footprint is one of the most challenging goals for cities, and as existing cities evolve and transform into smart cities, SEM becomes an integral part of the urban transformation. This article comprehensively reviews the different SEM technologies for different sectors (construction, transportation, public services, water and waste), the policies, and the current challenges and opportunities for SEM policy governance in India. Making urban energy smart can manage a city's energy footprint and have a positive impact on future carbon emissions.
\end{abstract}

Keywords: smart cities; smart energy management; India; energy efficiency; low-carbon mobility; water-energy nexus

\section{Introduction}

\subsection{Background}

India is rapidly urbanizing. Urban development is one of the main drivers of energy demand and consumption. The nation accounts for 18 per cent of the world's population and 6 per cent of global primary energy consumption [1]. India's urban population is expected to grow from 31.6 per cent to 57.7 per cent by 2050, with additional impacts on energy consumption and carbon emissions [2]. The task of managing and reducing energy demand, energy consumption and energy-related carbon emissions is often a challenge for urban planners [3,4].

In this context, it is important to address urban challenges such as sustainable transportation, access to reliable and clean energy, green and resilient infrastructure, and waste management through the principles of smart energy management (SEM). In particular, there is a need to integrate SEM principles in different sectors, such as buildings, transport, water, waste and public services, to reduce carbon emissions and achieve sustainable development goals (SDGs). This integrated SEM will also ensure the optimal utilization of available resources and reduce reliance on unsustainable energy sources.

To this end, The Energy and Resources Institute (TERI) and the University of New South Wales (UNSW) organized Australia-India knowledge exchange workshops on "Smart Energy Management for Sustainable Cities" in Sydney and Delhi. Sectoral experts and urban practitioners from local urban institutions, policy think tanks, academia and research institutions, as well as industry participated in the workshops. Through panel discussions chaired by sector experts, participants considered the way 
forward for integrated SEM in Indian cities. This paper combines the main results of the workshops and a comprehensive literature review to introduce the state of policy on SEM in India. It highlights SEM governance, SEM strategies and initiatives in different sectors, and potential challenges, drivers and opportunities for SEM in India. The review will contribute to knowledge creation and understanding on the SEM policy landscape in India.

\title{
1.2. The Definition of SEM
}

In order to build an understanding of SEM, it is important to first become familiar with the concepts and principles of energy management. Energy management can be defined as the science of planning, guiding, and controlling energy supply and consumption to maximize productivity and comfort, and minimize energy costs and pollution [5]. Simply put, energy management involves the conscious, wise and efficient use of energy. Energy management also requires the process of monitoring, controlling and saving energy, optimized energy utilization, management of energy resources, and active energy efficiency. With the rapid expansion of India's urban areas, managing the energy footprint is becoming a challenging target for cities. Therefore, energy management has recently become an integral part of urban transformation.

Taking into account local resources and the needs of stakeholders, smart cities are expected to become more autonomous and manage their energy footprints more effectively. In this paper, SEM entails energy management as an important component of smart cities. A smart city is a sustainable and efficient urban centre designed to provide a high quality of life for its residents by optimizing resources [6]. In this article, SEM is defined as follows:

\begin{abstract}
"Smart energy management is a component of smart city development aiming at a site-specific continuous transition towards sustainability, self-sufficiency, and resilience of energy systems, while ensuring accessibility, affordability, and adequacy of energy services, through optimized integration of energy conservation, energy efficiency, and local renewable energy sources. It is characterized by a combination of technologies with information and communication technologies that enables integration of multiple domains and enforces collaboration of multiple stakeholders, while ensuring sustainability of its measures." [7] (p. 57)
\end{abstract}

The mainstreaming of SEM involves the integration of energy technology systems, enabling policies, strategies, institutional change, awareness, training and capacity-building programmes, energy conservation measures and energy audits.

\section{SEM Policy Governance in India}

The Government of India (GoI) has been developing policies and programmes to guide the mainstreaming of SEM into urban planning. To meet citizens' energy needs and reduce carbon emissions, the Indian government has adopted a two-pronged approach, focusing on supply and demand. In the area of power generation, the focus is on greater use of renewable energy (solar and wind). In the current policy landscape, the impetus to reimagine national energy supply and demand management through technological advances is in place. In addition, in accordance with the intended nationally determined contributions (INDCs), a strategy has been developed to reduce the emission intensity of the GDP by 33-35 per cent by 2030 from 2005 levels and to achieve 40 per cent fossil-free power generation capacity by 2030 [8]. On the demand side, efforts are being made to improve energy efficiency through innovative policy measures that fall within the scope of the Energy Conservation Act of 2001. In this section, some of the key SEM policies are discussed.

\subsection{The Energy Conservation Act (EC Act), 2001, and Amended in 2010}

The Energy Conservation Act 2001 (EC Act), as amended in 2010, was enacted by the Ministry of Electricity (MoP) to reduce energy intensity. In 2002, the Bureau of Energy Efficiency (BEE) was established as the central statutory body for the implementation of the EC Act. The Act regulates 
the Energy Conservation Building Code (ECBC), standards and labelling of equipment and electrical appliances, and energy consumption norms for energy-intensive industries. It is estimated that energy consumption through the implementation of the ECBC will be reduced by at least 50 per cent by 2030 .

In addition, the Act requires the GoI and BEE to promote energy efficiency in all sectors. The law also requires designated agencies at the state level to enforce the law and improve energy efficiency. Through the Act, the BEE has launched a series of energy-saving initiatives in the areas of home lighting, commercial buildings, standards and home appliance labels. For example, the Energy Efficiency Labeling Program is designed to reduce equipment energy consumption without compromising on performance. The law also sets minimum energy standards for new commercial buildings across India.

\subsection{National Mission on Enhanced Energy Efficiency, 2010}

The National Mission on Energy Efficiency (NMEE), launched under the National Climate Change Action Plan on Climate Change (NAPCC), was launched under the EA 2001. The Energy Efficiency Services Limited (EESL), established as a business entity under the mission, provides market leadership. The goal of the NMEEE is to meet the country's energy needs and provide energy efficiency. During the full implementation phase, the NMEEE intends to save approximately 23 million tons of fuel per year and reduce carbon emissions by 95.55 million tons per year [9]. The first cycle of the Perform, Achieve and Trade (PAT) initiative (2012-2015) reduced carbon emissions by 31 million tons, or about 1.93 per cent of India's total emissions [9]. While the BEE recognizes the NMEE as one of its key tasks, PAT entails effective investment mechanisms and financial instruments, such as energy efficiency certificates. In addition, the mission pays greater attention to inter-sectoral linkages and close coordination between energy demand and supply sectors.

\subsection{National Mission for Sustainable Habitat, 2010}

The National Mission on Sustainable Habitat (NMSH), envisaged in the NPACC, aims to integrate climate change adaptation and mitigation into urban planning. This is achieved by improving the energy efficiency of buildings, managing solid waste and switching to public transport. The code estimates that energy consumption will be reduced by 50 per cent by 2030. In line with this mission, BEE has also developed energy efficiency design guidelines for multi-storey residential buildings in composite and hot and dry climates. In the area of green buildings and energy efficiency, a green building code has been incorporated into the workbook of the Central Works Department (CPWD). Draft building by-laws were also published to help state and territory governments incorporate their necessary provisions into their respective building by-laws. A number of activities envisaged under the NMSH were included in the Atal Recovery and Urban Transformation Mission (AMRUT). Examples include the implementation of pedestrian, non-motorized and public transport facilities, as well as the establishment and upgrading of urban green space, parks and recreation centres.

\subsection{National Solar Mission, 2010}

The National Solar Mission (NSM), launched under the NAPCC, envisages a comprehensive strategy for phased development of grid-connected and off-grid solar applications. According to the Ministry of New and Renewable Energy (MNRE), the aim is to provide an enabling environment for the penetration of solar technology in the country. The initial goal of the NSM was to generate 20 gigawatts (GW) grid-connected solar power. In 2014, the target was upscaled from $20 \mathrm{GW}$ to $100 \mathrm{GW}$ by 2022. It has separate goals and targets for solar cities, solar water heating, solar street lighting, solar cooking, refrigeration and other off-grid applications and rooftop systems. The Solar Cities programme is designed to incentivize each city to reduce projected demand for traditional energy by at least 10 per cent within five years. 


\subsection{Smart Cities Mission, 2015}

The Ministry of Housing and Urban Affairs (MoHUA) launched the Smart Cities Mission in 2015 to address governance and infrastructure concerns of the growing urban population of cities and to promote quality of life. By integrating the internet of things (IoT) technology, the mission aims to integrate smart technologies in different sectors to achieve sustainable urban development in an energy-efficient and cost-effective manner. The smart city proposals entailed two major aspects: (1) a pan city project, which includes information and communication technology (ICT) solutions such as an integrated traffic management system (ITMS), automated city level waste collection, e-governance and rooftop solar panels in government buildings; and (2) an area-based development (ABD) project, wherein a small area within the city is identified and is developed with identified smart solutions for improving its infrastructure, which then becomes a prototype for other parts of the city. The mission aims to create energy efficient urban spaces to reduce the burden on existing resources. As per the mission guidelines, 80 per cent of the buildings in the smart cities need to be energy efficient with a 'green building' design and 10 per cent of a smart city's energy demand should be met by solar energy.

\subsection{Draft National Energy Policy, 2017}

The National Energy Policy (NEP) prepared by NITI Aayog focuses on energy access for all, reducing dependence on fossil-fuel imports, promoting low-carbon development and sustainable economic growth. Considering energy is handled by several ministries, this policy aims to achieve national energy objectives through coordination between different ministries. The NEP aims to mainstream energy technologies and provide consumers with energy choices and prepare the Indian economy to be 'energy ready' by 2040.

Demand-based strategies relevant to integrating energy management for sustainable cities have been proposed under the NEP for transport, buildings and household (cooking) sectors. Under the transport sector, strategies such as transit oriented development, modal shift to rail-based mass transport systems, promotion of electric and hybrid vehicles, and ICT solutions have been proposed. Under the buildings sector, a shift towards energy efficient building materials, enforcement of ECBC, better urban planning, adoption of high efficiency lighting technologies and appliances, and under the housing sector, a shift towards modern fuels for cooking and improvement in the efficiency of cooking fuels and stoves has been proposed.

\subsection{Draft National Cooling Action Plan, 2018}

India mostly experiences a tropical climate and with its cities undergoing rapid urbanization, cooling requirements are projected to rise by 2.2 to 3 times (2017 baseline) in the next decade [10]. The implications of this increase will be significant through increased power generation capacity, peak load and carbon footprint. It is against this background that the Ministry of Environment, Forests and Climate Change (MoEFCC) has developed a draft National Cooling Action Plan (NCAP). The NCAP aims to promote sustainable and intelligent cooling practices across the country over the next 20 years. It covers cooling growth scenarios and strategies, transportation cooling, cold chain and refrigeration, air conditioning and refrigeration technologies, service sectors, and cross-cutting policies and regulations.

\section{SEM in Different Sectors}

Cities are complex ecosystems that cover a wide range of sectors, including construction, transportation, water, waste and public services. To understand the potential of integrated SEM for Indian cities, the workshop in Delhi focused on identifying challenges and opportunities for the adoption of SEM. Discussions focused on existing policies and strategies applicable to different sectors. Building on the results of the workshop and further comprehensive literature review, this section 
identifies SEM solutions and strategies for each sector, as well as the challenges for the adoption of SEM in Indian cities.

\subsection{Enhancing Sustainable Energy Management of Buildings}

Old or new, public or private owned, commercial or residential, single or multi-occupant buildings are facilities where people live, work, and play. They form the landscape of a city and are home for its people. At the same time, buildings are the largest energy consumers. Buildings account for over 40 per cent of India's energy consumption-this will soon increase to nearly 60 per cent [11]. In buildings, energy services such as cooling, heating, hot water, lighting, electricity and natural gas are used daily for the safety and comfort of the occupants. These facilities account for three quarters of total Greenhouse Gas (GHG) emissions in urban areas. [6]. As a result, cities need to make energy-efficient, smarter, greener and sustainable buildings.

The main objective of SEM solutions in buildings is to minimize the environmental impact of various energy services on the building lifecycle and reduce energy costs [7]. They should be able to optimize energy consumption and demand, manage occupant comfort, and help create household energy independence that will help sustain the grid (ibid.). SEM solutions in buildings fall into three categories based on their applicability: (i) solutions that address energy consumption by providing efficient control of building energy systems; (ii) solutions that deal with energy demand response; and (iii) solutions that integrate solar passive design and sustainable materials [6].

By integrating energy generation, storage, distribution, and automation, the solutions in the first approach provides greater comfort, functionality, and flexibility. In fact, optimizing operations and managing can save 20 to 30 per cent of building energy without changing system structure or hardware configuration (ibid.). Within this approach, variable speed chillers, home temperature automation control systems and adaptive fuzzy comfort controllers are the latest focus of smart heating, ventilation, and air conditioning (HVAC) systems efforts. Lighting controls and features such as appliance control gears, day lighting integration using building information modeling (BIM) tools, occupancy sensors, fixtures with photometric characters, and light-emitting diode (LED) lamps are common smart lighting solutions [12].

Demand response is another approach. Generally, most buildings are passive consumers of energy. However, in order to achieve the expected energy objectives, the role of buildings must be transformed from passive and unresponsive energy users to active participants in energy systems [13]. This paradigm shift can be achieved through micro-grids, demand response schemes, information and control systems to manage load and consumption, and energy storage equipment [6]. In the micro-grid concept, other variants are available according to the size and type of application. Examples include nanogrids, district energy networks, combined cooling and cooling systems, and medium-scale microgrids [14].

In a passive systems approach, building insulation, thermal mass, window placement, glass type and shading are key technologies [15]. Solutions in other approaches are most effective when combined with building insulation and solar passive solutions.

Some of these smart building energy systems and strategies are already in place in Indian cities. For example, smart metering, smart grid and energy internet, rooftop solar, net metering, smart lighting, LEDs, day lighting, and smart HVAC systems are being used to achieve a smart building architecture [16]. However, due to insufficient knowledge and limited expertise [17], many other advanced solutions (e.g., smart building energy management systems, micro- and nano-grids, home automation controls) are limited to small-scale or pilot projects. The large-scale application of SEM technologies in buildings will help engineers, planners, and designers in India to achieve the lowest energy cost targets and zero environmental impact on the building life cycle [18].

For example, smart metering, smart lighting, smart grids, rooftop solar, net metering, LEDs and smart HVAC systems are being used to implement intelligent building architectures. However, due to limited knowledge and expertise, many other advanced solutions (such as smart building energy 
management systems, micro and nano-grids, home automation control) are limited to small or pilot projects. The large-scale application of SEM technology in buildings will help engineers, planners and designers in India achieve the minimum energy cost target with zero environmental impact on the building life cycle.

With the Smart Cities Mission and the mission of harnessing renewable energy, the future of smart energy technologies in Indian architecture is very bright, and this area will significantly contribute to the future of the technological revolution. In addition, by deploying smart technologies, conventional buildings can be transformed into smart energy buildings.

\subsection{Improving the Water-Energy Nexus}

In order to ensure the effective management of water, the nexus between the water and energy sectors cannot be ignored. Water is a basic requirement for meeting energy demand and supply. Evidence shows that thermal power plants account for 87.8 per cent of the country's total industrial water consumption [19]. However, the water sector currently faces several problems and challenges that hinder the effective management of water resources. For example, India accounts for 18 per cent of the world's population, but only 4 per cent of its water resources [19]. Due to limited resources, the per capita water availability is on a decline, which increases resource pressure on the country's energy requirements. There is also loss of water in urban supply systems due to inefficient distribution mechanisms. A major concern in management of the water-energy nexus is that the supply systems have been functioning independently.

An integrated approach is required to ensure that the energy and water sectors are not managed in silos. SEM of water generally refers to "a holistic approach to managing this priceless resource, and the infrastructure systems surrounding its sourcing, treatment and delivery" (Environmental Leader, 2018). SEM is needed to identify energy utilized for water consumption, supply and distribution-either for public or private usage. This will improve efficiencies in the water systems and reduce wastage.

Smart technology in the water sector usually consists of four components: (i) digital output instruments (meters and sensors), which collect and transmit information in real time; (ii) supervisory control and data acquisition (SCADA) systems, which process information and remotely operate and optimize systems; (iii) geographic information systems (GIS), which store, manage, and analyze spatial information; and (iv) software applications, which support modelling infrastructure and environmental systems by managing and reporting data to improve design, decision making, and risk management [20].

Water is a significant requirement for coal-based power plants and nuclear power plants, as well as for renewable energy production. The different stages where water is utilized indispensably include extraction and refining of fuel and in thermal production of electricity. A reservoir water supply system helps to optimize water supply levels by estimating demand [21]. Other systems that support water monitoring are the real-time hydrological data acquisition and processing systems that collect water levels, water quality, and other relevant data via satellite imaging and other communication technologies; and the generation integrated operation systems that monitor dam and weir operations remotely [21].

The energy demand sector includes the agricultural, construction, industrial and household energy sectors [19]. For example, the percentage of households with electricity supply increased from 55 per cent in 2001 to more than 80 per cent in 2017 [22]. This scenario reflects the increase in household energy demand and the consequent water demand. The MoHUA's Smart City Mission aims to implement smart water solutions that collect real-time meaningful and actionable data from existing water networks [23]. Utilities can use this information to effectively distribute water. The mission's emphasis on artificial intelligence (AI), smart sensors, and technologies will improve leak detection by pinpointing leak locations, eliminate false leak alarms, enhance real-time monitoring of the network, and improve water quality issues and customer services [23]. An efficient pumping system is a key 
strategy to improve household water management. Emphasis on the reuse and recycling of wastewater in buildings should be supplemented by a decentralized water purification system at the city level.

To reduce the energy footprint of water and minimize wastage, Indian cities have begun to take some measures. The efficiency of water pumping systems is being improved in cities with appropriate rationalizing and pricing mechanisms. In Bengaluru, some apartment buildings have been built with smart water metering, which facilitates hourly water tracking and remote management of leaks [24]. The Indian Green Building Council's (IGBC) green cities rating system provides incentives to reduce water consumption and aid reduction by metering and monitoring water consumption. Alternative energy sources are also being utilized in high-water-consuming sectors. For example, solar energy is being used for electricity generation to ease the burden of water-intensive thermal power production processes.

In order to integrate SEM into the water sector, several factors need to be considered. Some of the challenges facing the water sector are the lack of proper metering, wherein the true cost of water prices is not calculated. An evaluation and water pricing mechanisms to measure the efficiency of the water systems (e.g., pumps) are rare. The automation of the water systems is very limited. The limited capacity of a household to heat water at any time (e.g., sun availability) is a challenge for renewable energy in the water sector. In addition, spatial, temporal and socio-economic changes and other political conditions can affect water availability. With the help of SEM practices, water and energy losses are likely to decrease and the efficiency of the water system can be improved.

\subsection{Achieving Smart and Low-Carbon Mobility}

Transport plays a pivotal role in the development of a country. A transportation network fosters passenger and freight movement across the country, thereby increasing national productivity and socio-economic growth. The increase in transport demand has made the transport sector one of the most energy- and carbon-intensive sectors in India. The transport sector accounts for 24 per cent of total energy consumption [25]. On the other hand, the sector accounts for 13.2 per cent of the total carbon emissions [26]. With growing concern about energy security and climate change, it is now recognized that the transport sector should reduce its reliance on fossil fuels, energy consumption and carbon footprint.

The energy consumption and carbon emissions of the transport sector are typically determined by factors such as vehicle efficiency, vehicle use and distance travelled, fuel and energy types, and overall system efficiency of transport infrastructure [27]. To promote energy-efficient and low-carbon growth in the road transport sector, the GoI has introduced several policies and programmes across passenger and freight segments. The main focus of the policies in this transport segment is on the improvement of vehicular technology through the implementation of progressive fuel efficiency norms and electrification.

With an objective to promote energy efficient low-carbon growth of the road transport segment, the government has introduced two major programmes: the Vehicle Fuel Efficiency Program and the National Electric Mobility Mission Plan (NEMMP) 2020. These are applicable for both passenger and freight road transport in India and are being implemented in a phased manner. Under the Vehicle Fuel Efficiency Program, the implementation of fuel economy standards is an effective regulatory instrument to reduce the average fuel consumption of vehicles. In 2017, the Ministry of Road Transport and Highways (MoRTH) came up with the first set of fuel economy norms for light duty vehicles (LDVs) in the passenger segment. These standards are based on the corporate average fuel economy (CAFE) norms and define the targets in terms of fuel consumption in liter $/ 100 \mathrm{~km}$.

Under the NEMMP, launched in 2013, the Faster Adoption and Manufacturing of (Hybrid and) Electric Vehicles (FAME) scheme was launched in 2015 by the Ministry of Heavy Industries and Public Enterprises to incentivize the production and promotion of electric vehicles (EVs). In addition to the private vehicle segment, the government has introduced EVs in multimodal public transport. In 2017, Nagpur became the first city in India to launch an electric mass transit project in India. A fleet 
of 200 electric vehicles (100 electric taxis and 100 e-rickshaws) was procured, and a cab aggregator provided the service platform for running the e-vehicles. Furthermore, several mobility solutions such as a public bicycle sharing scheme, intelligent transport management systems, electric feeders for last/first mile connectivity, integrated transport management platforms, and development of ICT applications have been proposed by several smart cities within the Smart Cities Mission.

The future of low-carbon transport should be highly efficient electric cars running on renewable electricity, a shift from private cars to public transport, better urban planning and investment in options that promote non-motorized transport (NMT) such as cycling and walking. In addition, the current electricity grid infrastructure will need to be reinforced if a significant level of transport electrification takes place. As the transport sector has implications on various other sectors, a cross-sectoral approach that incorporates reviewing the economic and environmental feasibility of sustainable mobility options should be undertaken. To achieve sustainable and low-carbon mobility in cities, the challenges highlighted in the discussions were the need for contextualized transport choices, informed decision making by policymakers, and sensitization of policy to citizens.

The recommendations suggested in the discussions included the promotions of cab aggregators/service providers such as Ola and Uber, provision of subsidies for EVs, and support for NMT options such as trams, as observed in various European countries. Cities also need to promote innovative solutions using ICT and efficient data and energy management. Policies for the transport sector should not be developed in isolation. Policy inputs from all sectors need to be taken into consideration.

\subsection{Optimizing Waste Management Processes}

From 2000 to 2015, the urban population of India almost doubled, while the amount of waste generated by the population increased by 2.5 times [28]. In addition, while the urban population has an annual growth rate of 3-3.5 per cent, urban waste generation is expected to increase by 5 per cent per year [29]. In this scenario, solid waste management is a major concern for cities. It is estimated that India's waste generation will reach 436 million tons by 2050 [30]. Effective waste management requires data management and integration at different levels, promoting the private sector and developing linkages between different sectors. Further, municipalities will need to focus on developing institutionalized and environment-friendly mechanisms to support proper waste disposal and better quality of life.

Intelligent energy management solutions that convert waste into useful energy can reduce the amount of waste generated and optimize the waste management process. A typical waste-to-energy (WtE) plant usually requires a minimum input of 300 TPD solid waste so as to make the system economically viable [16]. If large amounts of urban waste generated can be converted to energy, it can reduce the burden on conventional energy sources and the need for open space to dump unrecyclable waste. By 2050, India's WtE potential is estimated to become 556 megawatts (MW). However, these plants require diligence, adequate supply of quality waste, market infrastructure, and technical capacity [30]. Through proper support and the provision of smart technologies, municipalities can develop an active energy generation sector that has co-benefits for other sectors.

Effective technologies can be used for SEM in different areas of waste (collection, processing, and disposal). For example, radio frequency identification (RFID) technology, global positioning system (GPS) routing systems, and vacuum systems can reduce the time and effort spent on collection [31]. In waste treatment facilities, mechanical biological treatment and refuse-derived fuel (RDF) facilities ensure proper disposal of hazardous waste [31]. Moreover, sanitary landfills, bioreactor landfills, and solar integration mechanisms are treatment technologies that help convert excess waste into profitable energy [31].

The informal waste recycling industry is the entry point for introducing innovative and smart solutions. For example, intelligent recycling solutions ensure that informal waste sorting methods, such as manual rag-picking at landfills before the segregated waste is sent to recycling plants, are not 
only technically more advanced but also faster and safer to use for the workers. As a way forward, a smart waste management plan needs to be supported with the concept of circular economy.

According to Swachh Bharat Mission (Urban) data for 2018, 43 per cent of the total urban wards in India are now segregating their waste at the source [32]. In 2017, door-to-door collection coverage increased from 53 to 80 per cent [32]. In cities such as Panaji, Indore, Mysore and Muzaffarpur, there is a waste separation system, wherein separated waste is brought to the processing center [33]. Then, compost is made from wet waste, while only inert waste goes to the landfill. Sambyal [29] elaborates that Alappuzha in Kerala prioritizes segregation and reuse of waste at the household level, making it one of the cleanest cities in India.

It has accomplished decentralized waste management; 80 per cent of the households now own biogas plants and pipe composting systems. As part of the Clean Home Clean City programme, Alappuzha launched Thumburmuzhi in 2013, a model aerobic composting plant that composts animal carcasses [29].

A key challenge facing the waste sector in India is the need to increase manpower at the collection level. Waste segregation is an important obstacle and remains a daunting task. Despite the existing intelligent mapping and routing technologies, the segregation of waste, especially at the household level, is still limited. The sector requires a higher utilization of economical and user-friendly technical solutions.

Another core issue in the sector is the lack of accountability and transparency. Due to the limited knowledge of stakeholders (sometimes corruption) and the lack of innovative solutions, the methods used are not the optimal for effective waste management. Therefore, it is important to develop capacity building and awareness programmes for authorities and relevant citizens to respond to behavioural changes and incorporate smart practices into the waste management sector.

\subsection{Enhancing Efficiency of Public Service Delivery}

A range of urban public services such as street lighting, security management, video-surveillance, weather systems, and communication infrastructure provide safety, security, and information for citizens, while increasing the cities' competitiveness [34]. These public services need to be integrated with smarter, more energy efficient, and more innovative solutions for better service operations, management, and governance.

A range of urban public services, such as street lighting, security management, video surveillance, weather systems, and communications infrastructure, provide security, safety and information to citizens, while improving cities, combined with smarter, more energy-efficient, and more innovative solutions for better service operations, management, and governance.

SEM in public services helps city governments and utilities maintain and improve energy use, and to maximize the efficiency and quality of city services. Three different types of SEM solutions exist in the public services sector: (i) solutions that conserve, control, and monitor energy generated and distributed by utilities; (ii) solutions that store energy generated by customers or third-party members or the utility grid; and (iii) solutions that generate energy from natural resources, thereby creating relative or total energy independence from the grid [6].

A smart grid is an important technology for delivering utility-scale power to industrial, commercial, and residential areas in an efficient, reliable and safe way [6]. It consists of an independent energy network capable of exchanging electricity and operating systems in real time [6]. A micro/macro-scale smart grid can not only reduce energy loss, but also improve the utilization of renewable energy sources [35]. Smart substations and smart metering are the next steps in this direction.

Evidence suggests that smart substations [36] and advanced metering infrastructures [37] have improved the continuity of distributed supply and have had a positive impact on energy efficiency. Energy storage solutions (ESS) are used to store different types of energy (e.g., electricity, heat, kinetic energy). In urban public services, ESS can be used to integrate renewable energy and support demand-response plans. An important advantage of ESS is that customers or third-party energy 
producers can store energy from the utility grid during a lower price period and use it during a higher price period. Recent advances in energy storage technology include batteries, supercapacitors, flywheels, hydrogen fuel cells, compressed air storage, thermal storage, and mixed ESS [6,38]. Key applications of these technologies include battery-based grid systems, micro-grid and small-scale renewable energy technologies, and smart charging plug-ins for electric vehicles.

Finally, it is important to note that one of the goals of smart cities is to gradually migrate their electricity, thermal and data infrastructure to a complete renewable energy based systems [39]. Cities need to localize electricity consumption, provide low-carbon heating and cooling, and recycle energy and resources to maximize efficiency. Solutions that support this approach include solar photovoltaics (e.g., grid-connected, off-grid), solar collectors, centralized solar power plants, small and utility-scale wind turbines and geothermal energy. Other non-renewable resources with less impact, such as combined heat and power (CHP) and natural gas and biomass power generation, can better replace conventional power generation.

Local governments in India have been implementing smart energy strategies in public services. For example, district regional cooling systems, smart grids, smart metering, net metering and renewable energy integration are being planned or already used [16]. However, the lack of effective policies and regulations at the central, state and municipal levels, as well as inadequate guidelines, standards and business models, are obstacles to the large-scale use of widely available public service-based SEM technologies (e.g., energy storage, smart micro-grids). Integration of information modelling into urban management infrastructure (climate monitoring stations, lighting and power outage management controls, underground utility monitoring infrastructure, and data and communications management stations) is another key thrust area.

Following the recent announcement of 100 per cent electrification, GoI is making every effort to provide a reliable $24 \times 7$ of electricity to all its citizens and to promote reliable and transparent delivery mechanisms. In addition, with the launch of the Smart Cities Mission, hydropower, transportation, telecommunications and disaster management organizations are adopting the latest technologies to improve operational efficiency. Applying SEM solutions in public services can help achieve urban management goals through efficient distribution and transmission planning, utility transformation, and technology transformation [7].

Figure 1 presents a summary of key SEM solutions in different sectors, and Figure 2 presents the key challenges for SEM in different sectors.

Buildings
- Connection to
the smart grid
-Improve air
conditioning
system
-Improve lighting
systems \&
controls
-Improve heat
recovery \&
storage
-Hybrid
ventilation
systems
-Adaptive façade
systems
-High efficiency
generators
- Solar active
solution

Water
-Real-time data
acquisition \&
monitoring
-Smart metering
-Leak detection
-Efficient
pumping
systems
-Integrated
operation system
-Power, control \&
security systems
integration
-Water treatment
\& reuse facilities
-Storm water \&
urban flooding
management

\begin{tabular}{l} 
Transport \\
•EV charging \\
infrastructure \& \\
supervision \\
services \\
-Shift vehicle \\
technology - EVs \\
\& HEVs \\
-Intelligent traffic \\
management \\
systems \\
-Tolling \& \\
congestion \\
charging \\
-Integrated \\
mobility, multi- \\
modal \& shared \\
transport \\
-Improve public \\
transportation \\
-Improve \\
transportation \\
infrastructure \\
\hline
\end{tabular}

Waste
-Waste-to-energy
conversion
-Intelligent
monitoring of
general waste
-Smart Waste bins
-Dynamic
management and
routing
-Smart recycling
facilities
-Biological \&
advanced
thermal
treatment
-Industrial heat
recovery
-Solar integration

\begin{tabular}{l} 
Public services \\
-Smart sensors \\
-Public safety \\
-Video \\
surveillance \\
-Digital city \\
services \\
-Public street \\
lighting \\
management \\
-Smart District \\
Heating \& \\
Cooling \\
-Automated \\
distributed \\
control \\
-Renewable and \\
distributed \\
energy \\
generators \\
-Electrical \& \\
thermal energy \\
storage \\
\hline
\end{tabular}

Figure 1. A summary of key smart energy management (SEM) solutions in different sectors. 


\begin{tabular}{|c|c|c|c|c|}
\hline Buildings & Water & Transport & Waste & Public services \\
\hline $\begin{array}{l}\text { - Limited energy } \\
\text { storage, heating } \\
\text { \& cooling } \\
\text { technologies } \\
\text {-Insufficient } \\
\text { knowledge and } \\
\text { expertise for } \\
\text { increasing } \\
\text { efficiency } \\
\text { - Limited use of } \\
\text { smart building } \\
\text { architecture } \\
\text { techniques } \\
\text { - Limited use of } \\
\text { renewable } \\
\text { energy sources } \\
\text { - Low-scale } \\
\text { implementation } \\
\text { of innovative } \\
\text { projects }\end{array}$ & $\begin{array}{l}\text {-Inefficient } \\
\text { supply and } \\
\text { distribution } \\
\text { systems } \\
\text {-Low emphasis } \\
\text { on reuse \& } \\
\text { recycling of } \\
\text { wastewater } \\
\text {-High water } \\
\text { losses } \\
\text { - Limited smart } \\
\text { technologies \& } \\
\text { real-time data } \\
\text { collection } \\
\text {-Lack of } \\
\text { decentralized } \\
\text { treatment } \\
\text { systems } \\
\text {-Limited } \\
\text { utilization of } \\
\text { alternate energy } \\
\text { sources }\end{array}$ & $\begin{array}{l}\text {-Lack of } \\
\text { contextualized } \\
\text { low-carbon } \\
\text { mobility } \\
\text { solutions and } \\
\text { energy-efficient } \\
\text { infrastructure } \\
\text { - Limited } \\
\text { enforcement of } \\
\text { progressive fuel } \\
\text { efficiency norms } \\
\text {-Low penetration } \\
\text { of eco-friendly } \\
\text { vehicle options } \\
\text { - Limited public } \\
\text { transportation } \\
\text { facilities } \\
\text {-Low integration } \\
\text { of ICT solutions } \\
\text { and data } \\
\text { management }\end{array}$ & $\begin{array}{l}\text {-Low manpower } \\
\text { resources and } \\
\text { lack of citizen } \\
\text { awareness } \\
\text {-Absence of } \\
\text { effective waste } \\
\text { segregation, and } \\
\text { smart } \\
\text { technologies for } \\
\text { waste } \\
\text { management } \\
\text { - Limited waste- } \\
\text { to-energy } \\
\text { conversion } \\
\text {-Limited } \\
\text { intelligent } \\
\text { recycling } \\
\text { solutions } \\
\text {-Lack of overall } \\
\text { accountability \& } \\
\text { transparency }\end{array}$ & $\begin{array}{l}\text {-Low integration } \\
\text { with smart } \\
\text { systems } \\
\text {-Limited } \\
\text { utilization of } \\
\text { renewable } \\
\text { energy solutions } \\
\text { - Limited delivery } \\
\text { of low-carbon } \\
\text { public services } \\
\text {-Insufficient data } \\
\text { management \& } \\
\text { infrastructure for } \\
\text { operational } \\
\text { efficiency } \\
\text { - Lack of } \\
\text { interdepartmenta } \\
1 \text { coordination } \\
\text {-Ineffective policy } \\
\& \text { regulation } \\
\text { frameworks }\end{array}$ \\
\hline
\end{tabular}

Figure 2. Challenges for SEM solutions in different sectors.

\section{Overall Challenges and Opportunities for SEM in India}

In addition to the above sectoral challenges (Figure 2), different sectors face a range of cross-cutting challenges. Overcoming these challenges is necessary to facilitate and accelerate the implementation of SEM projects. These challenges must therefore be identified in order to allocate efforts and resources effectively and to reduce the main obstacles.

A range of multidisciplinary policy, management and administration tools and techniques are available to analyze the viability of policy and process development of SEM. Examples include from simple policy analysis tools such as SWOT analysis and root cause analysis to more advanced multi-criteria decision making, metric approach, Kaizen 5S method, and Hoshin Kanri X matrix [40]. However, PASTEL analysis is used in this paper as it outlines a novel approach for addressing the political (P), administrative (A), socio-environment (S), technological (T), economic (E), and legal (L) challenges and barriers that constrain the development of SEM in India [41]. The PASTEL analysis listed in Table 1 contributes to a better understanding of the challenges and implementation barriers of SEM.

Table 1. PASTEL (Political, Administrative, Socio-environment, Technological, Economic, and Legal) analysis for SEM in India.

\begin{tabular}{|c|c|}
\hline Area & Challenges \\
\hline Policy & $\begin{array}{l}\text { India lacks long-term and consistent SEM plans and policies. Despite, or perhaps } \\
\text { because of, overlapping policies and complex urban governance arrangements, } \\
\text { SEM governance in India remains fragmented and lacks political commitment } \\
\text { and support on the long term. }\end{array}$ \\
\hline Administrative & $\begin{array}{l}\text { There is a lack of portfolio alignment between different sectors, and lack of good } \\
\text { cooperation and acceptance amongst partners remains a major challenge. } \\
\text { Different actors in the energy ecosystem may have competing aims and objectives. } \\
\text { This poses a cross-sectoral design challenge. Long and complex procedures for } \\
\text { authorization of project activities, complicated and non-comprehensive public } \\
\text { procurement, difficulties in the coordination of high number of partners and } \\
\text { authorities, and fragmented ownership are major barriers for scaling-up of } \\
\text { projects. Public participation is rare and resources (institutional mechanisms, } \\
\text { human, infrastructure, and skills) to disseminate information are limited. }\end{array}$ \\
\hline
\end{tabular}


Table 1. Cont.

\begin{tabular}{cl}
\hline \multicolumn{1}{c}{ Area } & \multicolumn{1}{c}{ Challenges } \\
\hline Socio-Environment & $\begin{array}{l}\text { Government led initiatives, such as demonstration and pilot projects, are needed } \\
\text { for the majority of SEM actions in India. Negative effects of SEM related (e.g., } \\
\text { solar and wind projects) project interventions on the social and natural } \\
\text { environment may create inertia and interest in people. }\end{array}$ \\
\hline Technology & $\begin{array}{l}\text { Procurement businesses, skilled and trained personnel, and proven and tested } \\
\text { solutions and examples are inadequate. Industry interest in SEM projects is } \\
\text { limited, voluntary, and without strong influences, as the area is new and full of } \\
\text { risks and planning deficiencies. }\end{array}$ \\
\hline Economy & $\begin{array}{l}\text { Limited access to capital and insufficient external financial support/funding for } \\
\text { projects combined with economic crisis, risks and uncertainty in new } \\
\text { technologies, and high costs of products and materials remain impediments for } \\
\text { large-scale application of SEM solutions. }\end{array}$ \\
\hline Legal/Regulatory & $\begin{array}{l}\text { The extent of favorable and effective regulations and financial incentives for } \\
\text { innovative and new technologies is insufficient. The lack of consistent regulations } \\
\text { to standardize technologies is a major barrier. }\end{array}$ \\
\hline
\end{tabular}

There is a range of actions that governments and policymakers can promote to address energy-related challenges and achieve successful SEM in cities.

Integrated policy governance and effective decision-making-Energy management has traditionally been a part of either national or state government policy, while urban development and smart cities fall under the purview of state and city-level governments. Different stakeholders in different sectors with competing targets and goals may pose a significant SEM project and process design challenge. Therefore, the design process of SEM solutions needs cross-cutting initiatives. In addition, as the relation between energy and urban development becomes stronger, integration of SEM initiatives into all relevant government policies and operations becomes imperative. This should be supported by effective decision-making models. Multidisciplinary decision-making tools and techniques offer a variety of options and can facilitate the process of selecting the best solution within existing resources and support paradigm flexibility and applicability at any decision-making scale and variety [40]. Examples of existing decision-making methods for viable policy and process development include multi-criteria decision-making, process and content-oriented decision-making frameworks, decision-making matrixes, and qualitative decision-making tools [40].

Better governance will help the central, state governments and other stakeholders involved in different sectors to better coordinate to improve the effectiveness of energy management in smart cities-related policy decisions and public participation. SEM can be converged with the existing policy programmes by (i) establishing an inter-sectoral coordination committee that ensures integration, cross-referencing and liaison between appropriate organizations in buildings, transport, water and waste, and public services; and (ii) integration of SEM practices into relevant national and local policies (e.g., Smart Cities Mission, relevant missions under the NAPCC, urban development plans, building regulations, and procurement arrangements). Each of these actions can promote accountability and transparency in the decision-making process, which will contribute to smart energy governance in smart city development.

Provide better resources and infrastructure for technological advancements-Both human resources, and equipment, are required for adopting the intended SEM functions in smart cities. Funding and developing infrastructure for largescale applications of SEM initiatives remain a challenge. Therefore, governments must focus on innovative financing mechanisms and participation by both the public and private sectors. Governments should introduce adequate resources to drive informed decision-making, for investment prioritization in technology development, and to promote the scaling-up of SEM initiatives. 
Policies and resources to support the ongoing development of new technologies are critical to facilitating the large-scale application of SEM initiatives in cities. For example, domestic research and development can reduce the relatively high import and capital costs, increase the potential sources of revenue for businesses and promote the viability of advanced SEM technologies [42]. Pilot and demonstration projects are important in proving the feasibility of new technologies. Successful demonstrations reduce the risk of investing in these technologies and help ensure private investment in large-scale projects [42]. Examples of technologies that have proven technical feasibility through small-scale demonstration projects include cogeneration, compressed air energy storage (CAES), and next-generation battery technologies such as sodium-sulfur batteries and liquid electrolytes low-cell-based batteries [43].

Develop information, education and communication (IEC) strategies for stakeholder awareness and engagement-Policies, actions and programmes that increase stakeholder engagement, induce behaviour change, encourage the adoption of smart energy solutions amongst the home and business stakeholders and increase education and awareness amongst the public, private sector and other stakeholders are necessary. Primarily, policies and initiatives that inform the public and stakeholders about the benefits of SEM can be implemented.

Some of the suggested measures are listed as follows:

1. Develop and implement a range of fiscal incentives, grants or subsidies, access to finance, tax breaks, and product rebates can be employed by governments to engage business, industry, and civil society.

2. Promote media campaigns (TV, radio, press, social media), printed materials (such as brochures, pamphlets, advertisements, posters, leaflets and electronic newsletters), national campaigns and competitions, conferences and events, online tools, and websites and exhibitions.

3. Engage business, industry 'champions', builders, planners, architects, transport networks, real estate organizations, energy consultants, and energy managers in enterprises in projects (e.g., community organizations in district cooling/heating projects) and outreach programmes.

4. Develop comprehensive guides, compendiums, data bases, and handbooks that bring together global and national best practices, examples, methodologies, technology solutions, and existing policies, measures, and programmes.

Establish performance goals for effective implementation and monitoring-The effectiveness of policy implementation depends on the performance outputs. To this end, governments should set a range of performance targets and measures to achieve the required outcomes. A long-term performance framework should be developed to ensure on-going SEM initiatives and intrinsically energy-efficient and -sufficient new assets. The framework could include specific responsibilities and obligations for agencies, accountable for managing sectoral policies, setting goals, monitoring performance and reporting against these goals, and measuring outcomes.

Performance objectives can be majorly of two types: (i) quantitative targets for energy use, GHG emissions, and renewable energy; and (ii) action-oriented targets (e.g., upgrading designated facilities and awareness-raising programmes). Performance objectives should be regularly monitored, analyzed and updated to meet the policy commitments. This information should be used as appropriate for annual reporting purposes and should include detailed information on each sector.

\section{Conclusions}

As India's urban population is expected to grow significantly over the next couple of decades, there will be huge implications for energy demand and consumption [2]. The task of reducing carbon emissions and transforming India's urban centres into energy efficient and sufficient cities requires integration of smart energy management (SEM) practices in the different sectors. SEM can contribute to sustainable and resilient energy systems and services by combining affordable and reliable technologies, active energy efficiency, energy conservation measures, and management of resources. This paper 
provides a comprehensive analysis of the policy structure and challenges and opportunities for SEM in India. Three main conclusions can be outlined from the review.

First, since the enactment of the Energy Conservation Act in 2001, a series of policy and regulatory reforms have evolved to support SEM in India. Specifically, the Jawaharlal Nehru National Solar Mission (JNNSM) and the Smart Cities Mission have been playing key roles in transforming India's energy management landscape, transforming the energy sector from its infancy into one of the world's largest policy markets.

Second, through the perspectives of different stakeholders involved in the Australia-India Knowledge Exchange Workshop in India and a comprehensive literature review, key SEM strategies and challenges in different sectors are discussed. In addition, some PASTEL (Policy, Administrative, Socio-Environment, Technology, Economy, and Legal) challenges are identified. In addition to reducing carbon emissions, improving energy security and increasing employment opportunities, addressing these challenges will help accelerate the spread of SEM projects and practices in India [41].

Third, a range of policy, governance, resources, information, education, and awareness-oriented initiatives were proposed to address the challenges of SEM. Governments should use each of these recommendations as a starting point; the recommendations are not intended to be prescriptive or exhaustive. The policy recommendations identified in this review are very useful to policy makers around the world who are interested in addressing the challenge of implementing SEM policies and ultimately supporting emission reduction targets.

Finally, SEM offers a bright future for India's energy and economic development. India could intensify its efforts to develop and implement SEM practices to achieve key energy, environmental and economic development goals. However, SEM can only be achieved through collaborative efforts between governments, practitioners, utilities, regulatory boards, and industries. SEM could change India's energy landscape: it has the potential to revive the economy by achieving energy independence, reducing the energy deficit and pushing it to become a "green nation".

Author Contributions: Conceptualization, K.Y. and R.R.; methodology, K.Y. and R.R.; formal analysis, K.Y., R.R. and A.P.; investigation, K.Y., R.R. and A.P.; resources, K.Y. and R.R.; data curation, K.Y., R.R. and A.P.; writing—original draft preparation, K.Y., R.R. and A.P.; writing-review and editing, K.Y. and G.P.; visualization, K.Y., R.R. and A.P.; supervision, K.Y and G.P.; project administration, K.Y.; funding acquisition, K.Y.

Funding: This research was funded by UNSW-India Seed Grant, grant number RG181589.

Acknowledgments: We would like to thank the two reviewers for their comments and suggestions. The reviews have significantly helped to improve the paper.

Conflicts of Interest: The authors declare no conflicts of interest.

\section{References}

1. IEA. India Energy Outlook; International Energy Agency (OECD/IEA): Paris, France, 2015.

2. UN DESA. United Nations, Department of Economic and Social Affairs, Population Division. 2018. Available online: https://population.un.org/wup/Country-Profiles/ (accessed on 22 March 2019).

3. Danish, M.S.S.; Sabory, N.R.; Ershad, A.M.; Danish, S.M.S.; Yona, A.; Senjyu, T. Sustainable architecture and urban planning trough exploitation of renewable energy. Int. J. Sustain. Green Energy 2017, 6, 1-7.

4. Cajot, S.; Peter, M.; Bahu, J.M.; Koch, A.; Maréchal, F. Energy planning in the urban context: Challenges and perspectives. Energy Procedia 2015, 78, 3366-3371. [CrossRef]

5. Energy Lens. The What, Why, and How of Energy Management. 2018. Available online: https://www. energylens.com/articles/energy-management (accessed on 21 March 2019).

6. Calvillo, C.F.; Sánchez-Miralles, A.; Villar, J. Energy management and planning in smart cities. Renew. Sustain. Energy Rev. 2016, 55, 273-287. [CrossRef]

7. Mosannenzadeh, F.; Bisello, A.; Vaccaro, R.; D’Alonzo, V.; Hunter, G.W.; Vettorato, D. Smart energy city development: A story told by urban planners. Cities 2017, 64, 54-65. [CrossRef]

8. MoEFCC. India's Intended Nationally Determined Contribution-Towards Climate Justice. In The Ministry of Environment, Forest and Climate Change; Government of India: New Delhi, India, 2015. 
9. Rattani, V. Coping with Climate Change: An Analysis of India's National Action Plan on Climate Change; Mathur, T., Ed.; Centre for Science and Environment (CSE): New Delhi, India, 2018.

10. AEEE. The Need for a National Cooling Action Plan. 2018. Available online: https://www.aeee.in/nationalcooling-action-plan/ (accessed on 20 March 2019).

11. Chedwal, R.; Mathur, J.; Agarwal, G.D.; Dhaka, S. Energy saving potential through Energy Conservation Building Code and advance energy efficiency measures in hotel buildings of Jaipur City, India. Energy Build. 2015, 92, 282-295. [CrossRef]

12. Danish, M.S.S.; Senjyu, T.; Ibrahimi, A.M.; Ahmadi, M. Abdul Motin Howlader A managed framework for energy-efficient building. J. Build. Eng. 2019, 21, 120-128. [CrossRef]

13. Karnouskos, S. Demand side management via prosumer interactions in a smart city energy market place. In Proceedings of the 2nd IEEEPES International Conference and Exhibition on Innovative Smart Grid Technologies, Manchester, UK, 5-7 December 2011.

14. Guan, X.; Xu, Z.; Jia, Q. Energy-Efficient Buildings Facilitated by Microgrid. IEEE Trans. Smart Grid 2010, 1, 243-252. [CrossRef]

15. Pulselli, R.M.; Simoncini, E.; Marchettini, N. Energy and emergy based cost-benefit evaluation of building envelopes relative to geographical location and climate. Build. Environ. 2009, 44, 920-928. [CrossRef]

16. Arunkumar, P.K.; Malur, R.R. Energy Conservation in Built Environment in Smart Cities in View Point; Consulting Engineers Association of India: New Delhi, India, 2018; p. 13.

17. Rana, N.P.; Luthra, S.; Mangla, S.K.; Islam, R.; Roderick, S.; Dwivedi, Y.K. Barriers to the development of smart cities in Indian context. Inf. Syst. Front. 2019, 21, 503-525. [CrossRef]

18. Bhutta, F.M. Application of smart energy technologies in building sector-future prospects. In Proceedings of the 2017 International Conference on Energy Conservation and Efficiency (ICECE), Lahore, Pakistan, 20-23 November 2017.

19. TERI. Study on Assessment of Water Foot Prints of India's Long Term Energy Scenarios; Niti Aayog; Government of India and The Energy and Resources Institute: New Delhi, India, 2017.

20. Development Asia. What Is Smart Water Management? 2018. Available online: https://development.asia/ explainer/what-smart-water-management (accessed on 23 March 2019).

21. Development Asia. Sustainable Water Management for Smart Cities. 2017. Available online: https: //development.asia/case-study/sustainable-water-management-smart-cities (accessed on 23 March 2019).

22. CPR and Prayas. Trends in India's Residential Electricity Consumption. 2017. Available online: http: //cprindia.org/news/6519 (accessed on 23 March 2019).

23. Vaidya, A. Effective Water Management-Indispensable for Smart Cities. 2018. Available online: http://bwsmartcities.businessworld.in/article/Effective-Water-Management-Indispensable-for-smartcities-/09-05-2018-148681/ (accessed on 22 March 2019).

24. Raj, A. IoT-Enabled Smart Meter Helps Hourly Water Tracking at Apartments. 2018. Available online: https://timesofindia.indiatimes.com/city/bengaluru/iot-enabled-smart-meter-helps-hourly-watertracking-at-apartments/articleshow/62500517.cms (accessed on 22 March 2019).

25. TERI. TERI Energy E Environment Data Diary and Yearbook 2016/17; The Energy and Resources Institute: New Delhi, India, 2018.

26. UIC/IEA. Railway Handbook on Energy Consumption and CO2 Emissions; International Union of Railways \& International Energy Agency: Paris, France, 2016.

27. Gulati, V. National Electric Mobility Mission Plan (NEMMP) 2020; Department of Heavy Industry, Government of India: New Delhi, India, 2012.

28. Sacchdeva, M. How IoT Enabled Smart City Helps Tackle the Problem of Solid Waste Management in India. 2018. Available online: https://www.dqindia.com/iot-enabled-smart-city-helps-tackle-problem-solid-wastemanagementindia/ (accessed on 22 March 2019).

29. Sambyal, S.S. Waste Smart Cities. 2016. Available online: https://www.downtoearth.org.in/coverage/waste/ waste-smart-cities-54119 (accessed on 21 March 2019).

30. NIUA \& BEE. Sustainable Energy Integration in Smart Cities: Background Paper; National Institute of Urban Affairs \& Blue Earth Enterprise: New Delhi, India, 2015.

31. Research Nester. Smart Waste Management Market. By Technology (Smart Collection, Smart Processing, Smart Energy Recovery) \& By Geography 2016-2023. 2018. Available online: https:/www.reuters.com/ brandfeatures/venture-capital/article?id=59192 (accessed on 16 March 2019). 
32. Sambyal, S.S.; Agarwal, R. Is Swachh Bharat Mission Ensuring Waste Segregation Systems? 2018. Available online: https://www.downtoearth.org.in/blog/waste/is-swachh-bharat-mission-ensuring-wastesegregationsystems-61885 (accessed on 22 March 2019).

33. EMBARQ Network. Four Cities' Solutions to Sustainable Garbage Processing. 2019. Available online: https://www.smartcitiesdive.com/ex/sustainablecitiescollective/friday-fun-how-create-tomorrows-green-cities-today-s-garbage/1050616/ (accessed on 16 March 2019).

34. Belanche, D.; Casaló, L.V.; Orús, C. City Attachment and Use of Urban Services: Benefits for Smart Cities. Cities 2016, 50, 75-81. [CrossRef]

35. Hossain, M.S.; Madlool, N.A.; Rahim, N.A.; Selvaraj, J.; Pandey, A.K.; Khan, A.F. Role of smart grid in renewable energy: An overview. Renew. Sustain. Energy Rev. 2016, 60, 1168-1184. [CrossRef]

36. Huang, Q.; Jing, S.; Li, J.; Cai, D.; Wu, J.; Zhen, W. Smart substation: State of the art and future development. IEEE Trans. Power Deliv. 2017, 32, 1098-1105. [CrossRef]

37. Sharma, K.; Saini, L.M. Performance analysis of smart metering for smart grid: An. overview. Renew. Sustain. Energy Rev. 2015, 49, 720-735. [CrossRef]

38. Dubal, D.P.; Ayyad, O.; Ruiz, V.; Gomez-Romero, P. Hybrid Energy Storage: The Merging of Battery and Supercapacitor Chemistries. Chem. Soc. Rev. 2015, 44, 1777-1790. [CrossRef] [PubMed]

39. Mathiesen, B.V.; Lund, H.; Connolly, D.; Wenzel, H.; Østergaard, P.A.; Möller, B.; Nielsen, S.; Ridjan, I.; Karnøe, P.; Sperling, K.; et al. Smart Energy Systems for coherent 100\% renewable energy and transport solutions. Appl. Energy 2015, 145, 139-154. [CrossRef]

40. Danish, M.M.S.; Senjyu, T.; Zaheb, H.; Sabory, N.R.; Ibrahimi, A.M.; Matayoshi, H. A novel transdisciplinary paradigm for municipal solid waste to energy. J. Clean. Prod. 2019, 233, 880-892. [CrossRef]

41. Yenneti, K. The grid-connected solar energy in India: Structures and challenges. Energy Strategy Rev. 2016, 11, 41-51. [CrossRef]

42. Zame, K.K.; Brehm, C.A.; Nitica, A.T.; Richard, C.L.; Schweitzer, G.D., III. Smart grid and energy storage: Policy recommendations. Renew. Sustain. Energy Rev. 2018, 82, 1646-1654. [CrossRef]

43. Sioshansi, R.; Denholm, P.; Jenkin, T. Market and policy barriers to deployment of energy storage. Econ. Energy Environ. Policy 2012, 1, 47-64. [CrossRef]

(C) 2019 by the authors. Licensee MDPI, Basel, Switzerland. This article is an open access article distributed under the terms and conditions of the Creative Commons Attribution (CC BY) license (http://creativecommons.org/licenses/by/4.0/). 